\title{
Using Journey Mapping within Extension: A Tool for Supporting Behavior-Change Programs ${ }^{1}$
}

\author{
Colby Silvert and Laura A. Sanagorski Warner ${ }^{2}$
}

\section{Introduction}

Extension is an important change agency, and Extension professionals use innovative strategies to help target audiences adopt research-based practices and technologies (Rogers, 2003). Concepts from commercial marketing can be applied to behavior-change campaigns through an underused approach known as social marketing. Journey mapping is a conventional research technique "used to document and understand the many different steps or stages in a journey that a person may undertake" (Crosier \& Handford, 2012, p. 68). Journey maps can be developed with Extension clients to provide insight into their progression and decision-making from one place or state of being to another. A journey can be the steps a person takes when selecting plants for the landscape, the decision-making process used when identifying agricultural business strategies, or the steps a person takes when leaving a workshop and travelling to their home.

\section{Journey Mapping to Understand Behavior Change}

Behavior change takes place in incremental stages (Conroy \& Allen, 2010; Prochaska, DiClemente, \& Norcross, 1992; Prochaska, Redding, \& Evers, 1997; Warner, Galindo-Gonzalez, \& Gutter, 2014), and providing information at decision points is one of the most important features to consider when designing effective household behavior-change interventions (Stern \& Wolske, 2017). (For more information about stages of change, visit http://edis. ifas.ufl.edu/wc189).

Journey maps are visualizations of a person's experience as $\mathrm{s} /$ he works toward a goal, often with added information, such as feelings, at each point (Howard, 2014; LeFebvre, Taylor, \& Thomas, 2016). A journey map can be used to systematically track client experiences accessing and using services (Panzera et al., 2017). In addition to physical actions and decisions, journey maps may also be used to identify and illustrate problems, successes, and emotional responses to relevant services, developing a personal narrative of an experience (Panzera et al., 2017).

Journey mapping has been used in market research for over 50 years but has been drastically underused by social science and behavior-change researchers (Crosier \& Handford, 2012). This technique can be used to identify the stages a person may go through to reach some goal, such as the decision to adopt or change a behavior (Crosier \& Handford, 2012). Touchpoints, the interactions that may impact how a customer or client feels about a service or product, are also identified at each stage (Patterson, 2009). Journey maps have been lauded as a powerful tool for understanding the customer's point of view (Temkin, 2010), and in this document we discuss how they could be used by Extension professionals. A worksheet is also included

1. This document is AEC670, one of a series of the Department of Agricultural Education and Communication, UF/IFAS Extension. Original publication date April 2019. Visit the EDIS website at https://edis.ifas.ufl.edu for the currently supported version of this publication.

2. Colby Silvert, graduate student and graduate assistant; and Laura A. Sanagorski Warner, assistant professor, Department of Agricultural Education and Communication; UF/IFAS Extension, Gainesville, FL 32611.

The Institute of Food and Agricultural Sciences (IFAS) is an Equal Opportunity Institution authorized to provide research, educational information and other services only to individuals and institutions that function with non-discrimination with respect to race, creed, color, religion, age, disability, sex, sexual orientation, marital status, national origin, political opinions or affiliations. For more information on obtaining other UF/IFAS Extension publications, contact your county's UF/IFAS Extension office. 
in Appendix A for readers to apply journey mapping in real-world contexts.

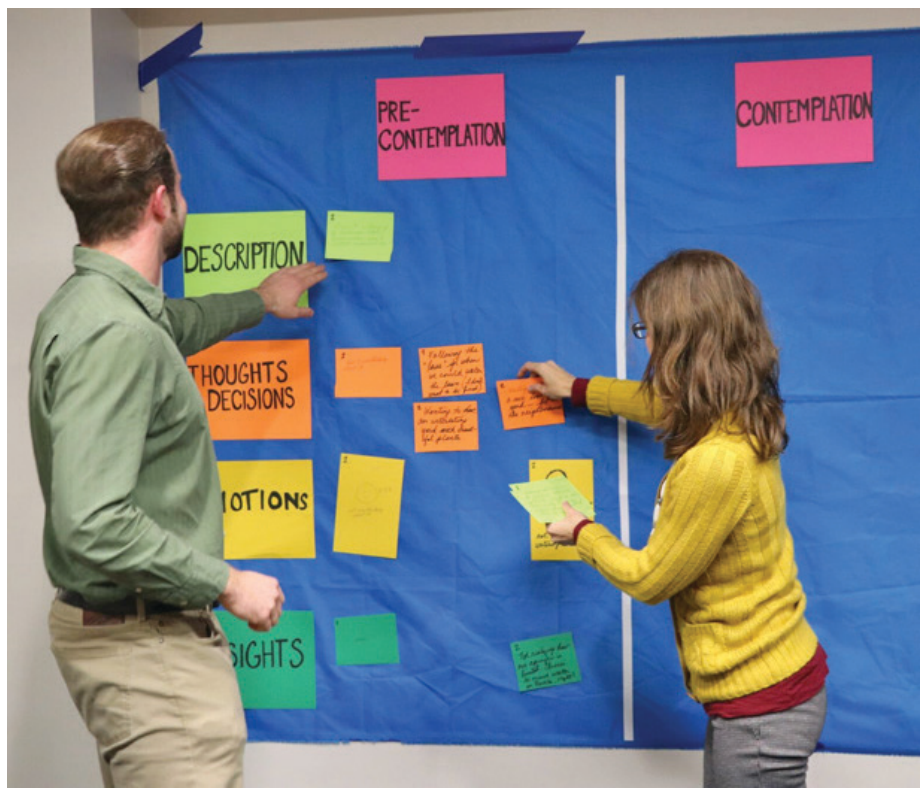

Figure 1. Data is collected to describe the first stage of a journey map on water conservation in the home landscape.

Credits: J. Shellhouse, UF/IFAS

Journey mapping has been recognized as a promising technique that can be used to design programs to encourage child water intake and bicycle safety habits (Essen, Hermsen, \& Renes, 2016) as well as to enhance students' reflection activities (Cooner \& Dickmann, 2006), evaluate drug-court programs (Crunkilton, 2009), and assess decision-making related to patient care (Westbrook, Coiera, Gosling, \& Braithwaite, 2007). There is a dearth of literature on applying journey mapping to social change and no record of application to Extension programming.

\section{Examples of Using Journey Maps in Behavior-Change Contexts}

While journey mapping has been predominately applied in the retail and product-design sectors, more recently the technique has been employed for social and behavior change, primarily in the public-health context (Esposito \& Zeledon, 2013). Examples include tracking the journeys of substance abusers in rehabilitation programs (Roarty et al., 2012), observation of shopping experiences for blind or visually-impaired individuals (Brahme, Gabriel \& Stenis, 2016), and evaluation of public health programs (Panzera et al., 2017).

The Special Supplemental Nutrition Program for Women, Infants, and Children (WIC) conducted a health program evaluation using journey mapping to understand economically disadvantaged families' access to nutrition and health services (Panzera et al., 2017). Journey mapping was used to investigate the reasons for dropping family enrollment since 2012 in Kentucky (Panzera et al., 2017). The program attempted to reconstruct the experiences of WIC participants and use journey mapping to collect data visualizing perceived emotions, issues, stigmas, and successes of those who stopped participating. WIC's data collection methods included direct observation, abbreviated participant observation to mimic participant experiences, and focus groups (Panzera et al., 2017). Data were analyzed to identify failures or opportunities by the program at various steps (touchpoints). The journey map is an excellent example of the visual output associated with this technique (see https:// s3.amazonaws.com/aws.upl/nwica.org/wic_journey_map. pdf), and it allowed the program staff to visualize user-reported benefits and barriers. For example, data demonstrated that many participants were satisfied with the financial benefits and access to nutritious foods through WIC but had trouble scheduling appointments and accessing transportation to appointments (Panzera et al., 2017).

Researchers also applied journey mapping in the social entrepreneurship field, testing an adapted version of the technique to identify key stakeholders and their needs in the establishment of a for-profit affordable greenhouse venture to benefit smallholder farmers in Sierra Leone (Ortbal, Frazzette \& Mehta, 2016). Journey mapping was used to aid project planning to efficiently and collaboratively form the stakeholder structure. Specifically, they engaged a diverse group of stakeholders whom they wanted to better understand to incorporate into the model and avoid foreseeable failures. The researchers explained that "the visual nature of journey mapping facilitates active participation and listening within a diverse group where members have various strengths and weaknesses and prefer different communication methods" (Ortbal et al., 2016, p. 250). In constructing the journey map, touchpoints were identified by participants at each anticipated stage in the launch of the venture and were categorized as pain points or opportunity points. These two categories were assigned according to participants' anticipated emotional responses at stages in the greenhouse establishment. The researchers aimed to reduce negative impacts of pain points and build on the strengths of opportunity points (Ortbal et al., 2016).

While we were unable to locate documented applications of journey mapping in Extension, the above example highlights how this tool can be used to understand stakeholder barriers and capacities, which is pertinent to Extension. Similarly, Extension professionals should appreciate and understand preferred communication means of their clients 
and should center program design around opportunities to break down barriers and increase benefits.

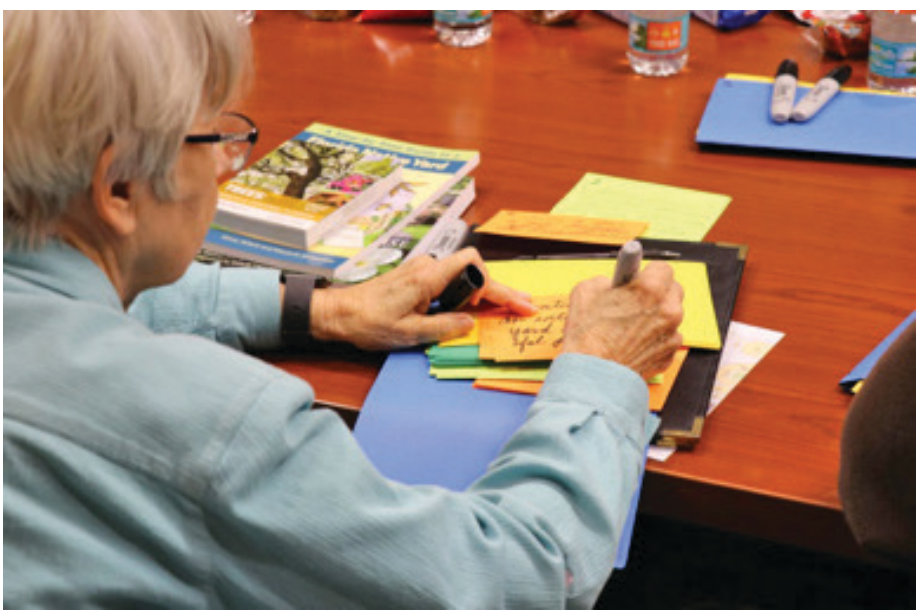

Figure 2. A participant fills out a data card during a journey-mapping session.

Credits: J. Shellhouse, UF/IFAS

\section{Possible Uses of Journey Mapping in Extension}

While journey mapping has only been modestly applied in the educational space (Ortbal et al., 2016), there is scope to integrate journey mapping (and adapted versions) into Extension program design, implementation, and evaluation. By visualizing the steps that a person takes to access an Extension program and identifying perceived barriers preventing her or his optimal experience in the program, an Extension professional can make programs more appealing and services more beneficial to clients. Below are some general areas in Extension where there is scope to test journey mapping.

\section{Program Design and Stakeholder Analysis}

In a similar application to the example above, in Extension, journey mapping could be used in the design and setup of an Extension program by documenting target participant/ client characteristics. First, the intended users of the program should be determined. Then the key stages in their anticipated journey should be identified to guide data collection. The journey's stages could be for the entire program or a portion, such as establishment. Within each stage of the journey, collected data should include anticipated participant and stakeholder emotions. Data for perceptions and predicted decision-making patterns may also be useful. These data are valuable to inform definition of touchpoints within each stage.

For example, if a new Extension program serving a crosssector of urban and semi-urban households aims to promote water conservation behaviors in the home landscape, under a hypothetical Action/Implementation stage, it may be relevant to record persons' attitudes on water conservation, their current irrigation behaviors, and whether the household hires outside landscaping services. Collection of this information would help determine users and non-users of conservation practices. The researcher should also record feelings and emotional responses at each stage.

Journey-mapping practitioners debate whether touchpoints should be designated before or after data collection (Ortbal et al., 2016). However, following the identification of the clients and stakeholders, an appropriate next step could be to use feedback at each stage to determine the touchpoints where targeted users may interact with the Extension service. A key touchpoint to consider when setting up a program could be the promotion of the program and the facilitation of access to relevant information to interested persons. For example, a touchpoint for the home landscape water conservation program could be participation by interested household representatives in informational sessions about launching the initiative. Another touchpoint could represent the process of accessing online materials about the program before deciding whether to participate. While the researcher may identify anticipated touchpoints, in a journey map reflective of client experiences, touchpoints should be informed by direct feedback.

Table 1. Hypothetical touchpoints during the establishment stages of a new Extension program.

\begin{tabular}{|c|l|l|}
\hline \multicolumn{1}{|c|}{ Stages } & \multicolumn{1}{|c|}{$\begin{array}{c}\text { Knowledge and } \\
\text { Information } \\
\text { Dissemination }\end{array}$} & $\begin{array}{c}\text { Deciding Whether } \\
\text { to Participate and } \\
\text { Enrollment }\end{array}$ \\
\hline Touchpoints & $\begin{array}{l}\text { Informational sessions } \\
\text { and meetings }\end{array}$ & $\begin{array}{l}\text { Sign-up procedure at } \\
\text { info sessions }\end{array}$ \\
\hline & $\begin{array}{l}\text { Interested potential } \\
\text { clients access online } \\
\text { materials (i.e., on social } \\
\text { media or webpage) }\end{array}$ & Online registration \\
\hline
\end{tabular}

In another Extension context, if a program aimed to encourage farmers to apply an alternative treatment to their crops, involvement in a field-day demonstration about application of the treatment could be a touchpoint identified through the data-collection process. Additional touchpoints in this example could describe how farmers access crop diagnosis and treatment information sources and consider them in making informed decisions to take action.

Analysis of the interactions at the identified touchpoints should be done by developing a set of criteria that infers where weak areas or barriers may impair clients' experiences (Patterson, 2009). To analyze touchpoints for stakeholders in the for-profit greenhouse venture in the previous section, researchers labelled touchpoints either pain points 
or opportunity points to account for perceived benefits or barriers (physical or emotional) for the participants (Ortbal et al., 2016).

An example of the analysis of touchpoints could be an inquiry into the process of seeking knowledge and information to guide the purchase of new water-efficient irrigation systems. If household participants claim that they have visited chain hardware stores and perceived that sales representatives were not knowledgeable or were unavailable, and participants left frustrated and confused about this topic, then data would describe this experience as a pain point. If, however, participants explained that a local Extension agent approached them, and they learned about the benefits of numerous irrigation options and were excited and felt well-informed, then this experience would be an opportunity point.

Table 2. Hypothetical analysis of decisions and feedback at touchpoints in water-conservation management of the home landscape.

\begin{tabular}{|l|l|l|}
\hline \multicolumn{2}{|c|}{ Access to Knowledge and Information on Water-Efficient } \\
Irrigation
\end{tabular}

While applying journey mapping to set up and design a program is largely based on anticipated experiences, by involving actual target users of the program, it can be a powerful technique to reduce disconnect between the program and its users. Aside from contributing to design, when the new program's staff participate in journeymapping data collection with target clients, they build relationships at an early stage to understand participants' needs and capacities.

\section{Distance Learning and Knowledge Sharing}

Journey mapping could be tested to facilitate user-friendly and appropriate methods to encourage Extension users' access to information- and knowledge-sharing opportunities. Modern Extension increasingly employs Information Communication Technologies (ICTs) such as, but not limited to, webpages, smartphone applications, or remote sensory innovations. Uptake and optimization of these tools require learning and training on their use, and their proper functioning with updated and relevant data. The application of journey mapping to track user experiences when accessing (or attempting to access) distance-learning tools resembles the use of journey mapping in the retail sector, frequently analyzing consumer online-shopping experiences. Touchpoints could describe data on participants' ease of access and their experience with a program. For example, Extension professionals could use journey mapping to track how a farmer uses a smartphone application to schedule her irrigation, or they could determine why a non-user farmer is reluctant to use such an application. The overall goal would be to assess where and why a user is satisfied and competent or becomes confused, reluctant, or frustrated during access and use processes.

\section{Program Evaluation}

Journey mapping allows an evaluation to zoom into the micro-levels of program implementation to assess impacts and participants' perceptions by "stepping into their shoes." For example, in the evaluation of the WIC nutrition program, the evaluators found that enrollment dropped due to transportation constraints when attempting to attend appointments (Panzera et al., 2017). While such a detail may be outside the scope of standard evaluation data, through journey mapping's participant-narrative approach, these potentially significant influences are revealed.

In Extension, journey mapping could be a participatory evaluation tool, using data-collection techniques such as focus groups, reflection sessions, and client shadowing. In 4- $\mathrm{H}$ programming, this technique might be used to understand how youth spend their time after school at specific points in a wellness program to identify possible increases in activity level. In an agricultural program, journey mapping could be used to determine the steps urban farmers take when accessing resources as a result of a new initiative. Participants would likely appreciate the efforts by the program to understand firsthand their reactions and experiences.

Analysis of touchpoints should illustrate what was supposed to happen or be delivered through the program and what actually happened and was delivered according to the participants. Constraints that prevented the target objectives from being achieved and strength areas where the program met or exceeded targets should be highlighted. Typically, the visual map(s) that results would be a collective compilation summarizing user feedback and data. 
While there could be many opportunities to integrate journey mapping into evaluations of Extension programs, for simplicity, the previous example of the residentiallandscape water conservation program will be used again. Following completion of the program, the standard evaluation may use indicators to estimate quantities of water conserved by the homes during the span of participation in the program. If there is high variance in the amounts of water consumed or conserved or a notable difference for two distinct groups (e.g., urban and less urban), a journey map could be used to dig deeper and track differences in client experiences at key stages to infer why the program impacted some clients more than others, and programmatic adjustments could be made to improve client experiences and better promote behavior change.

\section{Possible Data Collection and Analysis Approaches}

There are many approaches to data collection and analysis in the literature on journey mapping. In fact, concepts of journey mapping are often adapted for a variety of purposes and contexts, as implied in the above section, and methods are modified and devised accordingly. The majority of data collected for journey mapping is qualitative, and therefore, while a diverse group of subjects from key program areas is important, the sample size may be relatively small (as compared to a population study, for example). Below are suggested approaches for journey-mapping data collection and analysis that may be appropriate in Extension and research contexts.

\section{Orientation with the Program Design and Journey Mapping}

Depending on the journey map's purpose, an external facilitator may reduce bias that could arise from data collection by a program staff person. One of the first steps is to become familiar with the Extension program's design, key objectives, and processes intended to reach and facilitate change for clients. This may include review of program manuals, proposals, and interviews with administrators and Extension professionals involved with the program. Upon review of background information, Extension professionals or researchers should outline the key stages to examine during data collection. In the WIC journey map referenced above, the three key stages focus on the clinic, retail outlet, and kitchen.

Generally, broad stages should be proposed before data collection, and then more specific touchpoints will arise from the participant data. For example, during a focus group, if multiple participants highlight an interaction point that affected their experience, the researcher would likely add this as a touchpoint to the journey map.

\section{Shadowing and Direct Observation}

In the retail sector, the mystery shopper is applied in journey mapping to discover barriers that negatively impact consumer experiences. In Extension, a similar approach could be useful to test whether resources and processes are accessible to and effectively serving clients. A simple example could be to ask individuals unfamiliar with a smartphone application for monitoring their home landscape irrigation to watch a recommended tutorial and try to properly use the application. Notes should record points when they experienced difficulty and/or points when they were comfortable and found the tutorial and application helpful.

\section{Focus Group and Reflection}

Focus groups and reflection activities allow participants to be actively involved in the journey-mapping process. If the aim is to examine distinct groups (i.e., small-scale farmers vs. medium-scale farmers), focus-group meetings might be facilitated separately, or subgroups could be formed during activities. It is important, first, that participants in a focus group are briefed on the purpose of the data collection and the concept of journey mapping. Data-collection activities should be interactive, fun, and designed appropriately for the individuals present. The facilitator(s) can use visuals, such as colored notecards or post-it notes to categorize responses and discussion themes. Consider alternatives to written or verbal data. For example, faces could be drawn to describe emotions at stages in the journey. During the focus group, a journey draft could be mapped, allowing participants to assess whether the visual accurately reflects their experiences. During a focus group, an environment of respect and openness should be promoted, and all feedback should be documented, including direct quotes, before any internal analysis takes place. It is also recommended facilitators take photographs of visuals and/or group notes to facilitate accurate transfer of data.

\section{Analysis and Interpretation}

An analysis framework is important to guide using collected data for the construction of a journey map. Various techniques have been applied to data analysis for journey mapping. A potential approach to designing the framework is to have a horizontal axis with stages or progression of time and a vertical axis with data categories (Howard, 2014). The following example template was used to visually 
record participant feedback when designing the greenhouse social venture in Sierra Leone.

In this example, broad stages were identified before data collection, and more specific touchpoints were later added based on participants' data. To gauge emotional responses, pain points were identified, and participants were asked to describe whether certain actions at stages evoked emotions. Those emotions were added to the template as positive, neutral, or negative (Ortbal et al., 2016).

\section{Conclusion}

Journey mapping is an innovative technique Extension professionals can use to better understand how their target audiences make decisions or change. To learn to apply the technique in Extension contexts, a simple worksheet is found in Appendix A with instructions to create a journey map. There is substantial potential for Extension to adopt journey maps as a tool to support program design and evaluation. Applications in Extension should be tested and shared to recommend good practices.

\section{Stakeholder Group: Smallholder Farmers}

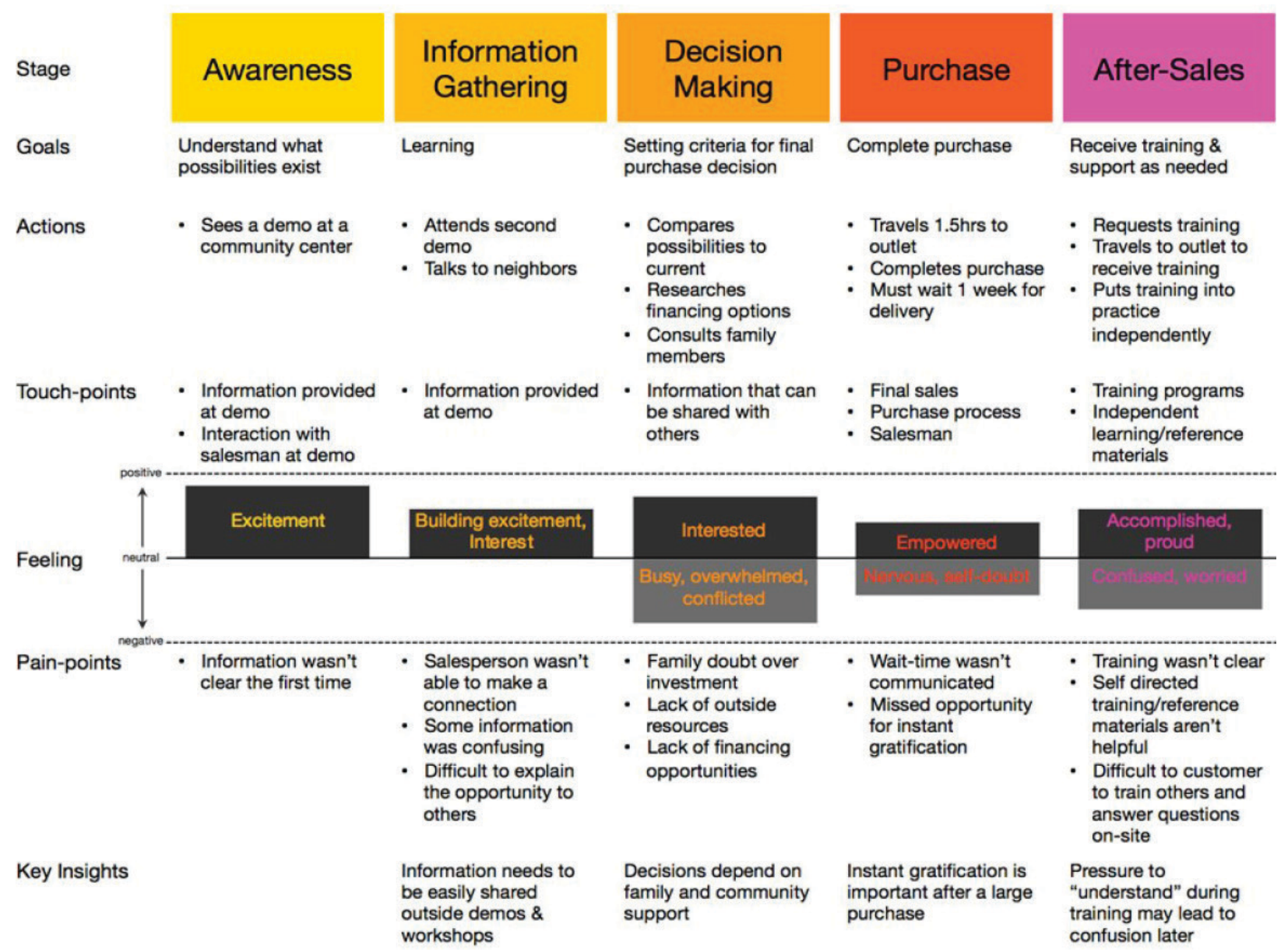

Figure 4. Example Journey Mapping Template. Reprinted from "Stakeholder Journey Mapping: An Educational Tool for Social Entrepreneurs," by K. Ortbal, N. Frazzette and K. Mehta, 2016, Procedia Engineering, 159, p. 256 


\section{Acknowledgment}

This work was supported by the USDA National Institute of Food and Agriculture, Hatch project 1018367.

\section{References}

Brahme, M. E., Gabriel, L., \& Stenis, P. V. (2016). Don't stop believing: Mapping distance learners' research journeys. Journal of Library \& Information Services in Distance Learning, 10(3-4), 118-136. doi:10.1080/1533290X.2016.1206779

Conroy, D. M., \& Allen, W. (2010). Who do you think you are? An examination of how systems thinking can help social marketing support new identities and more sustainable living patterns. Australasian Marketing Journal, 18(3), 195-197.

Cooner, D., \& Dickmann, E. (2006). Assessing principal internships and habits of mind: the use of journey mapping to enhance reflection. Innovate: Journal of Online Education, 2(4). Retrieved from http://nsuworks.nova.edu/innovate/ vol2/iss $4 / 4$

Crosier, A., \& Handford, A. (2012). Customer journey mapping as an advocacy tool for disabled people: A case study. Social Marketing Quarterly, 18(1), 67-76. doi:10.1177/1524500411435483

Crunkilton, D. (2009). Application review of journey mapping. Journal of Technology in Human Services, 27(2), 162-173. doi:10.1080/15228830902755879

Esposito, M., \& Zeledon, J. (2013). 5 ways you can use journey maps to help change behavior. Washington, D.C.: National WIC Association. Retrieved from https://www. nwica.org/blog/5-ways-you-can-use-journey-maps-to-helpchange-behavior\#.XOPvL_ZFyUk

Essen, A. V., Hersen, S., \& Renes, R. J. (2016). Developing a theory-driven method to design for behaviour change: two case studies. Proceedings of the 2016 Design Research Society 50 Anniversary Conference, Brighton, UK. Retrieved from https://static1.squarespace.com/ static/55ca3eafe4b05bb65abd54ff/t/5747666b60b5e9b8141b ebe1/1464297071450/71+Van+Essen.pdf

Howard, T. (2014). Journey mapping: A brief overview. Communication Design Quarterly Review, 2(3), 10-13. doi: $10.1145 / 2644448.2644451$
LeFebvre, C., Taylor, O., \& Thomas, V. (2016, June). Aligning journeys, jobs, and value for more relevant and effective social marketing programs. Presentation at the University of South Florida Social Marketing Conference, Clearwater, FL.

Ortbal, K., Frazzette, N., \& Mehta, K. (2016). Stakeholder journey mapping: An educational tool for social entrepreneurs. Procedia Engineering, 159(Humanitarian Technology: Science, Systems and Global Impact 2016, HumTech2016), 249-258. doi:10.1016/j.proeng.2016.08.170

Panzera, A. D., Bryant, C. A., Hawkins, F., Goff, R., Napier, A., Schneider, T., ... O’Rourke, K. (2017). Mapping a WIC mother's journey: A preliminary analysis. Social Marketing Quarterly, 23(2), 137154. doi:10.1177/1524500417692526

Patterson, L., (2009). Managing Touch point value: 10 steps to improve customer engagement. Retrieved from https:// www.visionedgemarketing.com/images/articles/managing\%20touch\%20point\%20value $\% 2010 \% 20$ steps $\% 20$ to $\% 20$ improve\%20customer\%20engagement.pdf

Prochaska, J. O., DiClemente, C. C., \& Norcross, J. C. (1992). In search of how people change: applications to addictive behaviors. American Psychologist, 47, 1102-1114.

Prochaska, J. O., Redding, C., \& Evers, K. (1997). The Transtheoretical Model and stages of change. In K. Glanz, F. M. Lewis, and B. K. Rimer (Eds.), Health Behavior and Health Education: Theory, Research and Practice (2nd Edition). Jossey-Bass Publications, Inc.

Roarty, L., Wildy, H., Saggers, S., Conigrave, K., Wilson, M., Di Nicola, K., \& ... Faulkner, J. (2012). 'My journey map': Developing a qualitative approach to mapping young people's progress in residential rehabilitation. Contemporary Drug Problems: An Interdisciplinary Quarterly, 39(4), 715-733. doi:10.1177/009145091203900406

Rogers, E. M. (2003). Diffusion of Innovations (5th edition). New York, NY: Free Press.

Stern, P. C., \& Wolske, K. S. (2017). Limiting climate change: What's most worth doing? Environmental Research Letters, 12(9). doi: 10.1088/1748-9326/aa8467

Tassi, R. (2009). Customer Journey Map. Service design tools. Retrieved from http://www.servicedesigntools.org/ tools/8

Warner, L., Galindo-Gonzalez, S., \& Gutter, M. S. (2014). Building impactful extension programs by understanding 
how people change. University of Florida Cooperative

Extension Electronic Data Information Source (AEC527).

Retrieved from http://edis.ifas.ufl.edu/wc189

Westbrook, J. I., Coiera, E. W., Gosling, S. A., \& Braithwaite, J. (2007). Critical incidents and journey mapping as techniques to evaluate the impact of online evidence retrieval systems on health care delivery and patient outcomes. International Journal of Medical Informatics, 76(2-3), 2007, 234-245. doi:10.1016/j.ijmedinf.2006.03.006

\section{Appendix A}

Journey-Mapping Instructions and Worksheet

1. On top of the journey map, summarize the behaviorchange scenario by answering the following questions: Who is the client? What is State A (before behavior change)? What is State $B$ (after or during behavior change)?

For example:

Client: A resident in an urban neighborhood

State A: Uses a traditional sprinkler system and is unaware of water wastage

State B: Installs and uses a smart irrigation system to conserve water in the home landscape

2. At each stage, add information in the boxes from the client about what s/he is (or was) doing and the emotions s/he is (or was) feeling at the time. The journey should be a progression from Stage 1 (State A), to the Final Stage (State B) of implementation or maintenance of the change.

For example: At Stage 1 Doing, the resident is learning about the importance of water conservation in the landscape but using a traditional sprinkler system. S/he feels confused and helpless about how to start making changes.

3. Adapt journey mapping for your work! This is only a simple example that can be applied in a variety of contexts. A journey may have more or less than four stages, and you may collect information other than emotions and actions depending on the purpose of your journey map. Remember, stages can be described through creative alternatives to words, like drawing faces to represent emotions. 


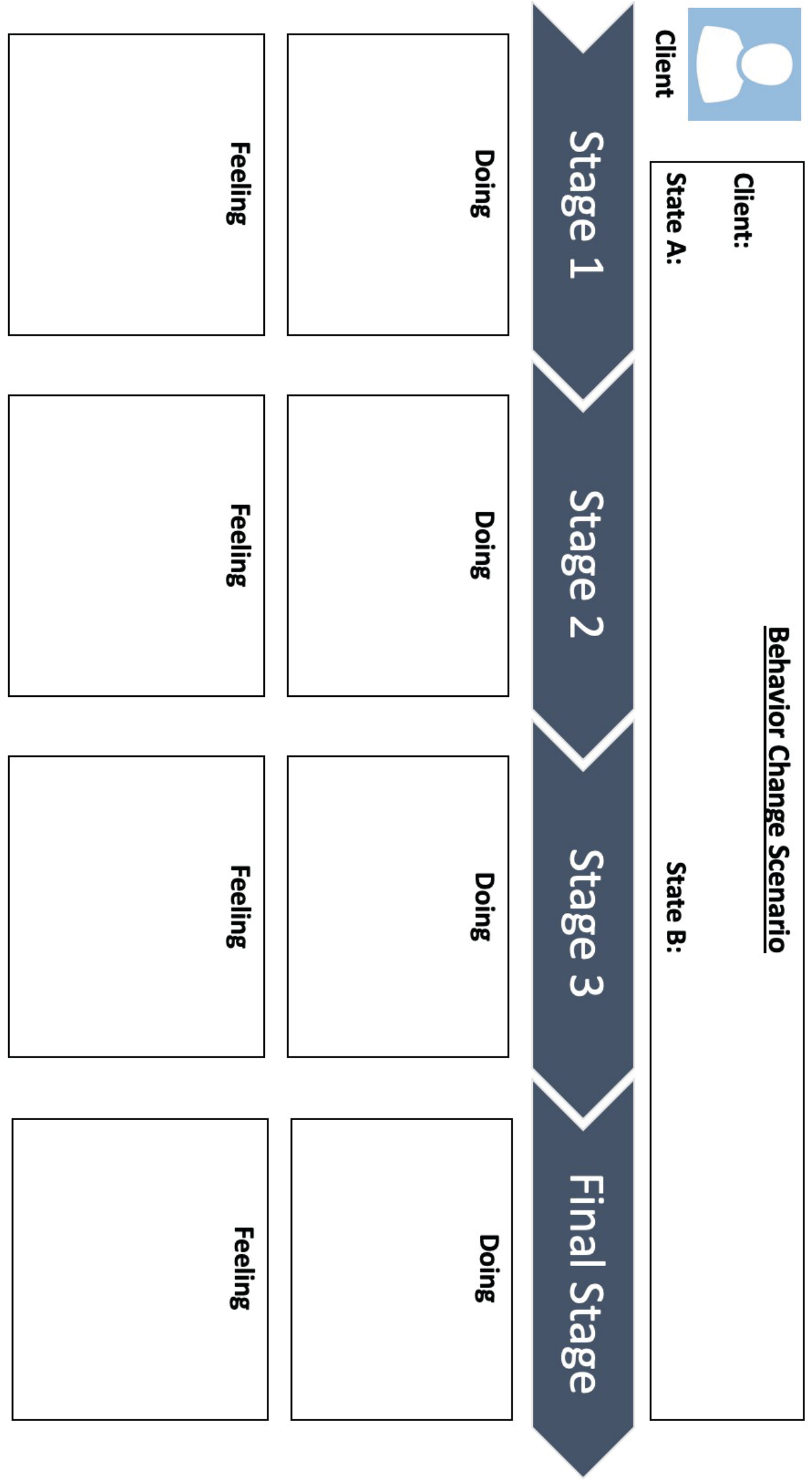

